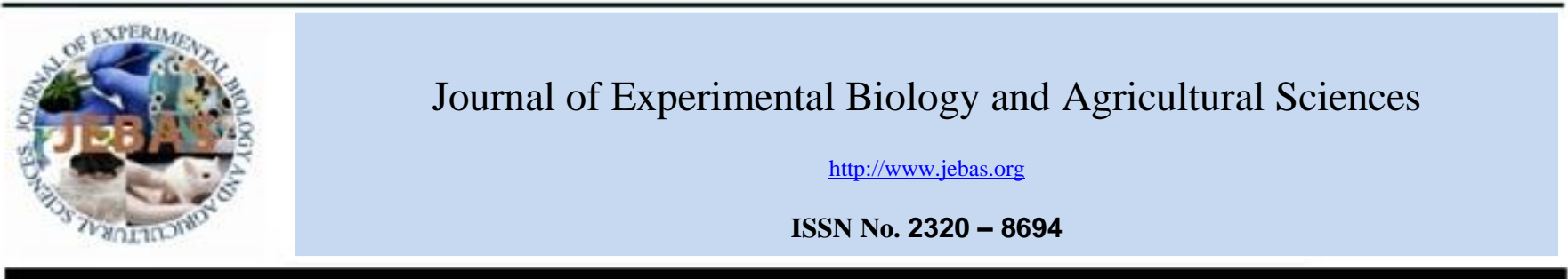

\title{
IN VITRO ANTIOXIDANT POTENTIALS AND HEPATOPROTECTIVE EFFECTS OF Asystasia vogeliana (BENTH) LEAF EXTRACTS AGAINST PARACETAMOL-INDUCED HEPATIC INJURY IN RATS
}

\author{
Emeka Hillary Ugwuanyi ${ }^{*}$, Chukwuneke Samuel Udem, Ifeanyi Innocent Madubuinyi
}

Department of Veterinary Physiology and Pharmacology, Faculty of Veterinary Medicine, University of Nigeria, Nsukka, 410001 Enugu State, Nigeria.

Received - September 03, 2020; Revision - November 02, 2020; Accepted - December 10, 2020

Available Online - December 30, 2020

DOI: http://dx.doi.org/10.18006/2020.8(6).839.848

\section{KEYWORDS \\ Antioxidant \\ Asystasia vogeliana \\ Hepatotoxicity \\ Paracetamol \\ Rats}

\begin{abstract}
This study was aimed to investigate the antioxidant potentials of methanol and petroleum ether leaf extracts of Asystasia vogeliana against paracetamol-induced liver injury in rats. For estimation of antioxidant potentials, in vitro radical scavenging assays were carried out using DPPH, FRAP, and ABTS. For in vivo study, twenty-five male Wistar rats weighing 100-120 g were randomized and assigned into 5 groups (I-V, $\mathrm{n}=5$ ). Further, Paracetamol (PCM) at $2 \mathrm{~g} / \mathrm{kg}$ was used to induce acute hepatotoxicity orally. Rats in group I received distilled water $(10 \mathrm{ml} / \mathrm{kg}$ ) only. While, the rats of groups II, III, and IV received MLEAV (200 $\mathrm{mg} / \mathrm{kg})$, PLEAV $(200 \mathrm{mg} / \mathrm{kg})$, and a standard hepatoprotective reference drug silymarin $(25 \mathrm{mg} / \mathrm{kg})$ respectively for 5 days before PCM induction. Rats in group $\mathrm{V}$ received distilled water for 5 days before PCM induction. Blood and liver samples were collected for hematology, serum biochemistry, and histopathology analyses using standard procedures. In vitro assays revealed that MLEAV showed significant $(P<0.05)$ increases in antioxidant activity compared with PLEAV. Further, significant $(P<$ $0.05)$ reductions in the activities of ALT and ALP while a significant $(P<0.05)$ increases in the activity of antioxidant enzymes (CAT, SOD, and GPx) were reported in the group II and III compared with group V. There were also no observable lesions in their hepatocytes. Results of the study can be concluded that MLEAV elicited more in vitro and in vivo antioxidant activities than PLEAV, thus it protects the liver of rat from PCM-induced hepatotoxicity. Therefore, MLEAV could be used as a hepatoprotective agent for the clinical management of liver damage.
\end{abstract}

* Corresponding author

E-mail: emeka.ugwuanyi @unn.edu.ng (Emeka Hillary Ugwuanyi)

Peer review under responsibility of Journal of Experimental Biology and Agricultural Sciences.

Production and Hosting by Horizon Publisher India [HPI] (http://www.horizonpublisherindia.in/).

All rights reserved.
All the articles published by Journal of Experimental Biology and Agricultural Sciences are licensed under a Creative Commons Attribution-NonCommercial 4.0 International License Based on a work at www.jebas.org.

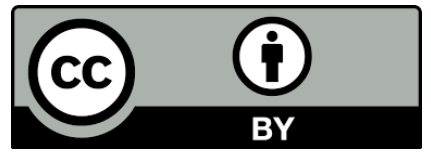




\section{Introduction}

Asystasia vogeliana (Benth) is a green straggling under-shrub, which belongs to the family Acanthaceae. The leaves of the tree are simple, opposite, ovate, and decussate without stipules. The flowers are zygomorphic and usually associated with colored bract (Popoola et al., 2017). A. vogeliana is widely used in traditional medicine as a remedy for hepatitis in Nsukka, Enugu State, Nigeria. It is commonly known as “'ogwu iba ocha n'anya' by Nsukka people which literarily meaning is a drug for treating hepatitis (Okoli, 2015). Indigenous use of $A$. vogeliana revealed that its infusion with the leaves of other plants such as Cassia alata, Cymbopogon citrus, and fruit juice of Citrus aurantifolia showed higher fidelity level in the management of malaria, chronic fever, gonorrhea, and leprosy (Popoola et al., 2017).

Oxygen is vital for aerobic life processes. However, about $5 \%$ or more of the inhaled $\mathrm{O}_{2}$ is converted to reactive oxygen species (ROS), (Phaniendra et al., 2015). When the generation of ROS overtakes the antioxidant defense of the cells, the free radicals start attacking various biomolecules such as proteins (Stadtman \& Levine, 2000), lipids (Yla-Herttuala, 1999), and DNA (Marnett, 2000), thus leading to several physiological disorders (Phaniendra et al., 2015).

Antioxidants are chemical substances that biotransform free radicals to harmless molecules by donating their electrons to free radicals. Antioxidants have gained increasing interest due to their protective roles in pharmaceutical and food industries against oxidative damage, and in animals against oxidative stress damage in biomolecules (Gulcin, 2020). Thus, antioxidants carry out their actions either by reducing the energy of the free radical or suppressing radical formation or breaking chain propagation or repairing damaged and reconstituting membrane (Sahu et al., 2009; Gulcin, 2020). Phenolics compounds have been associated with antioxidant activity due to their high free radical scavenging activities (Rezaie et al., 2015).

Acetaminophen (paracetamol) induced hepatotoxicity is a frequently used model for liver damage study, for screening hepatoprotective activity of natural medicines (Ezzat et al., 2012). Acute liver injury is a common consequence of taking an overdose of acetaminophen (Liu et al., 2019).

The application of herbal drugs in managing liver diseases has increased globally, because of the belief that herbal drugs are less toxic and have minimum side effects. Also, due to the undesirable therapeutic effects associated with orthodox drugs, the application of traditional medicine including herbal remedies has gained favor as better alternative management (Ali et al., 2009; Girish et al., 2009; Ali et al., 2019).
There is a dearth of information on the antioxidant capacity of the $A$. vogeliana and its hepatoprotective effects on animals. Therefore, the current study was aimed to investigate the in vitro and in vivo antioxidant potentials of the A. vogeliana leaf extracts. The study also evaluated the hepatoprotective effects of the leaf extracts on paracetamol-induced hepatotoxicity in Albino Wistar rats.

\section{Materials and Methods}

\subsection{Plant collection}

The study was carried out in 2017, for this A vogeliana leaves were collected from Nsukka, Enugu State, Nigeria. The collected $A$. vogeliana samples were identified by a plant taxonomist, Department of Pharmacognosy and Phytotherapy, University of Nigeria, Nsukka. The plant specimen (Px UNN / 0015) was kept in the department's herbarium for ease of reference.

\subsection{Experimental animals}

The study was carried out using 25 healthy male Albino Wistar rats weighing between 100-120 g. These experimental animals were obtained from Diamond Research Farm, Nsukka. The animals were housed in the department's laboratory animal units. Two weeks of acclimatization was allowed to the animals before the experiment started. During this period, these experimental animals were fed with commercial pelletized feed (Vital feed) ${ }^{\circledR}$ and water ad libitum. The rats were managed according to the Guide for the Use and Care of Laboratory Animals of the National Research Council (National Research Council, 2010). Ethical approval was taken from the Ethical Committee, University of Nigeria, (no. ECUN/15/78756).

\subsection{Chemicals and drugs}

Methanol and petroleum ether were purchased from Sigma Aldrich Company Missouri, USA. Silymarin (Silybon- $70^{\circledR}$ ) was purchased from Micro Labs Limited, India. Paracetamol was purchased from Emzor Pharmaceutical Company Limited, Nigeria. The reagents used were of analytical quality.

\subsection{Extraction of plant material}

A. vogeliana leaves were air-dried on a laboratory bench at ambient temperature $\left(26^{\circ} \mathrm{C}-28^{\circ} \mathrm{C}\right)$. The leaves were pulverized into a coarse powder using a hammer mill (JS-390, Japan), and 200g of the powdered leaves was soaked in $1000 \mathrm{ml}(80 \% \mathrm{v} / \mathrm{v})$ petroleum ether for $48 \mathrm{~h}$ and shaken at $2 \mathrm{~h}$ interval. The extract was refined using filter paper (Whatman No.1). The extract was later concentrated in vacuo by a rotatory evaporator. The extract was labeled as petroleum ether leaf extract of A. vogeliana (PLEAV) and then kept at $4^{\circ} \mathrm{C}$ in the refrigerator till the time of use. The marc was air-dried, reweighed, and cold macerated in $1000 \mathrm{ml}(80 \% \mathrm{v} / \mathrm{v})$ methanol for 3 days at ambient 
temperature $\left(26^{\circ} \mathrm{C}-28^{\circ} \mathrm{C}\right)$. The extract was obtained similarly as described in petroleum ether. The extract was labeled as methanol leaf extract of A. vogeliana (MLEAV).

\subsection{In vitro antioxidant assays}

\subsubsection{DPPH radical scavenging activity}

1, 1 - diphenyl - 2 - picrylhydrazyl (DPPH) radical scavenging activity of the two leaf extracts MLEAV and PLEAV were determined by adopting the procedure described by (Sahu et al., 2013), and as modified by (Iqbal et al., 2015). Each of the extracts was dissolved in a suitable volume of methanol to give final concentrations which ranges from 10 to $160 \mu \mathrm{g} / \mathrm{ml}$. Ascorbic acid solutions which served as the standard solution was also prepared in methanol using the same concentration range. Two milliliters (2 $\mathrm{ml}$ ) of each solution were put into a test tube and mixed with $4 \mathrm{ml}$ of $0.3 \mathrm{Mmol} / \mathrm{L}$ DPPH. A control solution was prepared by adding methanol $(2 \mathrm{ml})$ to $0.3 \mathrm{Mmol} / \mathrm{L}$ DPPH. The experiment was carried out in triplicate. The solutions were mixed well and left in the dark for $30 \mathrm{~min}$. After $30 \mathrm{~min}$, the solutions were analyzed on a UV-VIS spectrophotometer (JenWay ${ }^{\circledR}$, UK) at $517 \mathrm{~nm}$. The antioxidant activity was evaluated using the formula:

$$
\% \text { Inhibition }=\frac{\mathrm{A}_{\mathrm{C}}-\mathrm{A}_{\mathrm{S}}}{\mathrm{A}_{\mathrm{C}}} \times 100
$$

Where $A_{C}$ and $A_{S}$ are the absorbances of the control and sample (extract) respectively.

\subsubsection{Ferric reducing antioxidant potential (FRAP)}

Ferric reducing antioxidant potential (FRAP) of the two extracts (MLEAV and PLEAV) was done according to the method proposed by Benzie \& Strain (1996), and as modified by (Sahreen et al., 2010). In this assay, ferric ions are reduced to ferrous ions in the presence of an antioxidant (or a reducing agent) which forms a blue-colored ferrous tripyridyl triazine complex $\left(\mathrm{Fe}^{2+}-\mathrm{TPTZ}\right)$ at $\mathrm{pH}$ 3.6. The change is monitored spectrophotometrically at $593 \mathrm{~nm}$ (Huang et al., 2005). Two milliliter (2 ml) of $0.2 \mathrm{M}$ phosphate buffer (pH 6.6) and $2.0 \mathrm{ml}$ of 10 $\mathrm{mg} / \mathrm{L}$ potassium ferricyanide $(0.1 \% \mathrm{w} / \mathrm{v})$ solutions were mixed with 2. $0 \mathrm{ml}$ of each extracts solution. The mixture was then incubated in a water bath at $50{ }^{\circ} \mathrm{C}$ for $20 \mathrm{~min}$. Thereafter, $2.0 \mathrm{ml}$ of $100 \mathrm{mg} / \mathrm{L}$ trichloroacetic acid solution ( $10 \% \mathrm{w} / \mathrm{v})$ was added to the mixture. An aliquot of $2.0 \mathrm{ml}$ of the mixture was combined with $2.0 \mathrm{ml}$ of distilled water and $0.4 \mathrm{ml}$ of $0.1 \%(\mathrm{w} / \mathrm{v})$ ferric chloride $\left(\mathrm{FeCl}_{3} .6 \mathrm{H}_{2} \mathrm{O}\right)$ solution. The absorbance of the mixture reaction was taken at $700 \mathrm{~nm}$ after 10 min. The ferric reducing antioxidant power of the extracts was expressed as gallic acid equivalent.

2.5.3 ABTS $^{+}$(2, 2'-azido-bis 3-nylbenzithiazoline-6-sulphonic acid) radical scavenging assay

Antioxidant activity of $A$. vogeliana extracts regarding $\mathrm{ABTS}^{+}$ decolorization assay was measured using the method reported by
Re et al. (1999) with some modifications (Bursal \& Gulcin, 2011). The solution of $\mathrm{ABTS}^{+}$radical used was prepared by reacting ABTS $(9.5 \mathrm{ml}, 7 \mathrm{mM})$ with potassium persulfate $(245 \mu \mathrm{L}, 100 \mathrm{mM})$ and thereafter, the volume raised to $10 \mathrm{~mL}$ with distilled water. The solution was kept in the darkroom at room temperature for $18 \mathrm{~h}$ and then diluted with potassium phosphate buffer $(0.1 \mathrm{M}, \mathrm{pH}$ 7.4) to an absorbance of $0.70( \pm 0.02)$ at $734 \mathrm{~nm}$. The antioxidant activity of the sample was estimated using the following:

$$
\% \text { Antioxidant activity }=\frac{\left(\mathrm{A}_{C}-\mathrm{A}_{\mathrm{S}}\right)}{\mathrm{A}_{\mathrm{C}}}
$$

Where $A_{C}$ and $A_{S}$ are the absorbances of the control and sample (extract) respectively. The control was prepared by adding $10 \mu \mathrm{L}$ of methanol in place of the sample. All the measurements were carried out in triplicate.

\subsection{Acute toxicity test}

Oral acute toxicity and median lethal dose $\left(\mathrm{LD}_{50}\right)$ of $A$. vogeliana was done using MLEAV adopting the OECD Acute Toxic Class Method (OECD, 2001).

\subsection{Acetaminophen-induced acute hepatotoxicity}

Induction of acute hepatotoxicity was done by oral administration of paracetamol (PCM) @ 2g/kg on days 6 and 7 (Biswas et al., 2010).

\subsection{Experimental design}

Twenty-five male Wistar rats weighing 100-120 g were randomized and assigned into 5 groups $(\mathrm{I}-\mathrm{V}, \mathrm{n}=5)$. Paracetamol (PCM) $2 \mathrm{~g} / \mathrm{kg}$ was used to induce acute hepatotoxicity orally. Rats in group I received distilled water $(10 \mathrm{ml} / \mathrm{kg})$ only. The rats in groups II, III, and IV received MLEAV (200 mg/kg), PLEAV (200 $\mathrm{mg} / \mathrm{kg}$ ), and silymarin $(25 \mathrm{mg} / \mathrm{kg})$ respectively for 5 days before PCM induction. Rats in group V received distilled water for 5 days before PCM induction and PCM induction was done on days 6 and 7.

All the groups were kept on fasting for 24 hours before the PCM induction except group I. All treatments were given orally. On day 8 , blood samples were collected through medial cantus (Provencher-Bollinger \& Everds, 2010) with capillary tubes into plain bottles and sodium ethylene diamine tetra acetic acid (EDTA) bottles from each rat. The animals were anesthetized under mild ether by exposure in a closed container via the "opendrop" method. The animals were euthanized later by cervical dislocation. Blood samples without anticoagulation were left to clot at room temperature and the sera were harvested by centrifugation at $1500 \mathrm{rpm}$ for $10 \mathrm{~min}$. These were used for liver function tests, and antioxidants assessment. Blood samples in EDTA bottles were used for hematological examinations such as 
red blood cell count, total white blood cell count, packed cell volume. Sections of the liver were isolated and kept in $10 \%$ formalin solution for histological examinations.

\subsection{Hematology}

Hematological studies were conducted immediately after collection, following standard procedures. Packed cell volume (PCV) was estimated by the microhematocrit method (Thrall \& Weiser, 2002). Hemoglobin concentration was evaluated by the cyanomethemoglobin method (Higgins et al., 2008). Red blood cell and total leucocyte counts were carried out using the hemocytometer method (Coles, 1968).

\subsection{Determination of Liver and Kidney function parameters}

Randox reagents commercial kit (Randox Laboratories, UK) was used in assaying the serum activities of ALT, AST, and ALP and concentration of total bilirubin via spectrophotometeric method. Renal markers (urea and creatinine concentrations) were assayed by the kinetic method (Blass et al., 1974; Rock et al., 1987).

\subsection{In vivo antioxidant assessments}

Glutathione level was determined in the serum following the method of Ellman (1959). Superoxide dismutase (SOD) activity was measured according to the method of Marklund (1992). Catalase activity was determined following the method as described by Aebi(1983). Glutathione peroxidase activity was determined using the method of Rotruck et al. (1973).

\subsection{Histology}

The livers of the animals were isolated and fixed in $10 \%$ buffered formalin for histological examinations. Thereafter, the livers were embedded in paraffin, and sections cut at $5 \mu \mathrm{m}$ were stained with hematoxylin and eosin following the procedures as described by Bancroft \& Stevens (2002). The liver sections were then examined under a light microscope for histological changes.

\subsection{Data analysis}

The data collected were analyzed using One-Way Analysis of Variance (ANOVA) with aid of SPSS version 22. The least significant difference (LSD) post hoc test was used in separating the variant means. Probability level $(P<0.05)$ was considered significant.

\section{Results}

\subsection{Effect of MLEAV and PLEAV on DPPH, FRAP and ABTS $^{+}$-based in vitro antioxidant assays}

The results of the in vitro antioxidant activity assays (DPPH, ABTS, and FRAP) of MLEAV and PLEAV are shown in Figures 1, 2, and 3

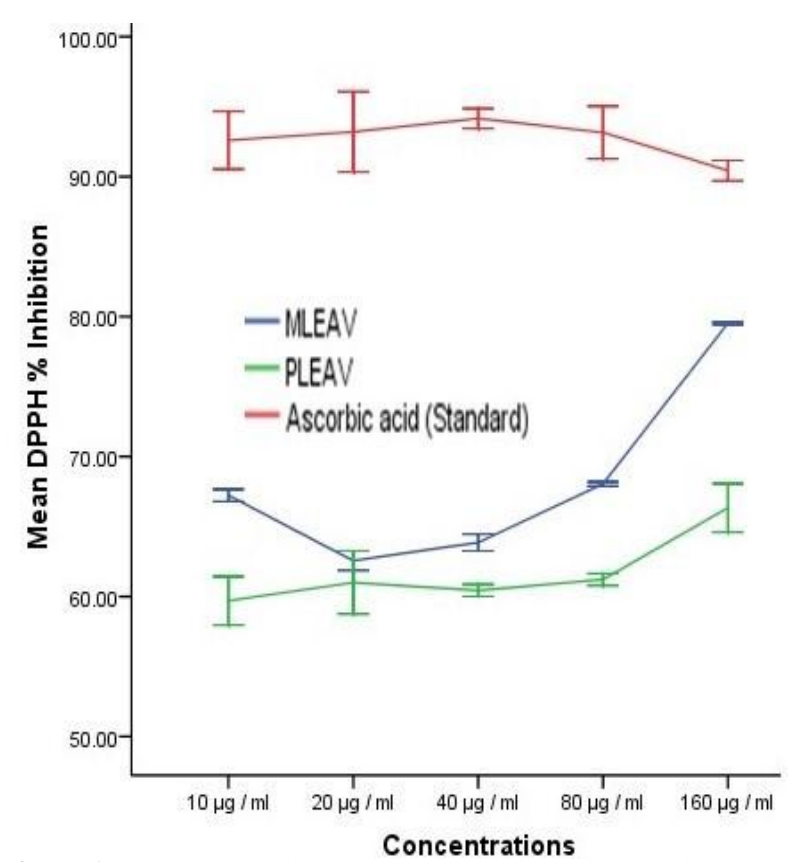

Figure 1 Mean percent free radical scavenging activities of MLEAV and PLEAV as per DPPH assay after an incubation of $30 \mathrm{~min}(\mathrm{n}=3)$. MLEAV = Methanol leaf extract of Asystasia vogeliana ; PLEAV= Petroleum ether leaf extract of Asystasia vogeliana.

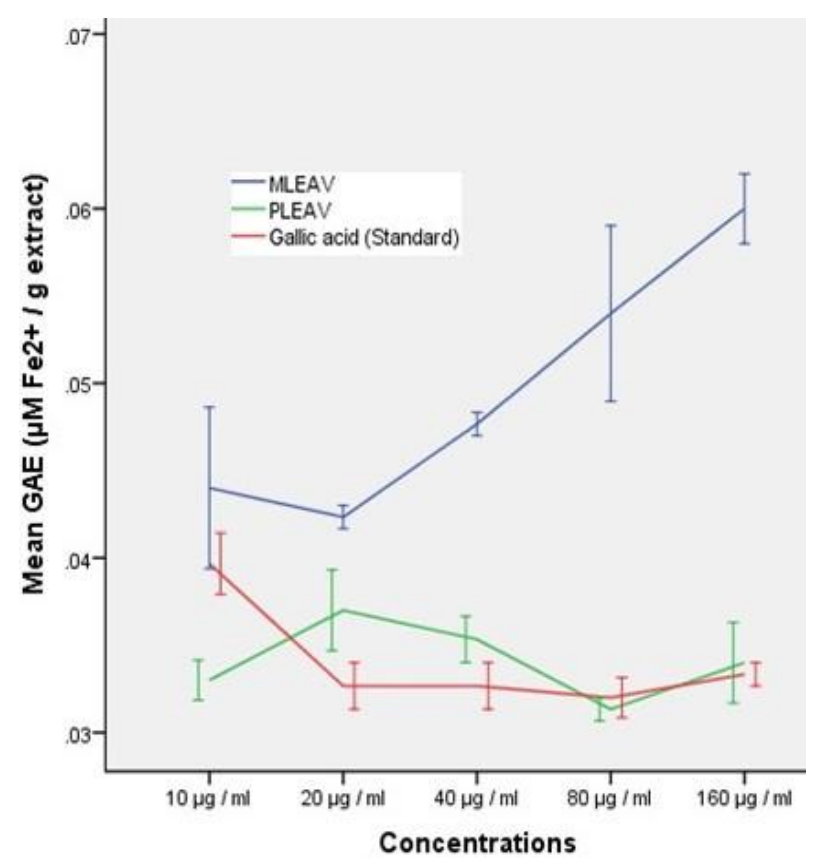

Figure 2 Mean ferric reducing antioxidant potential (FRAP) of MLEAV and PLEAV expressed as gallic acid equivalents (GAE). Results are presented as mean \pm SEM $(n=3)$. MLEAV $=$ Methanol leaf extract of Asystasia vogeliana; PLEAV= Petroleum ether leaf extract of Asystasia vogeliana. 


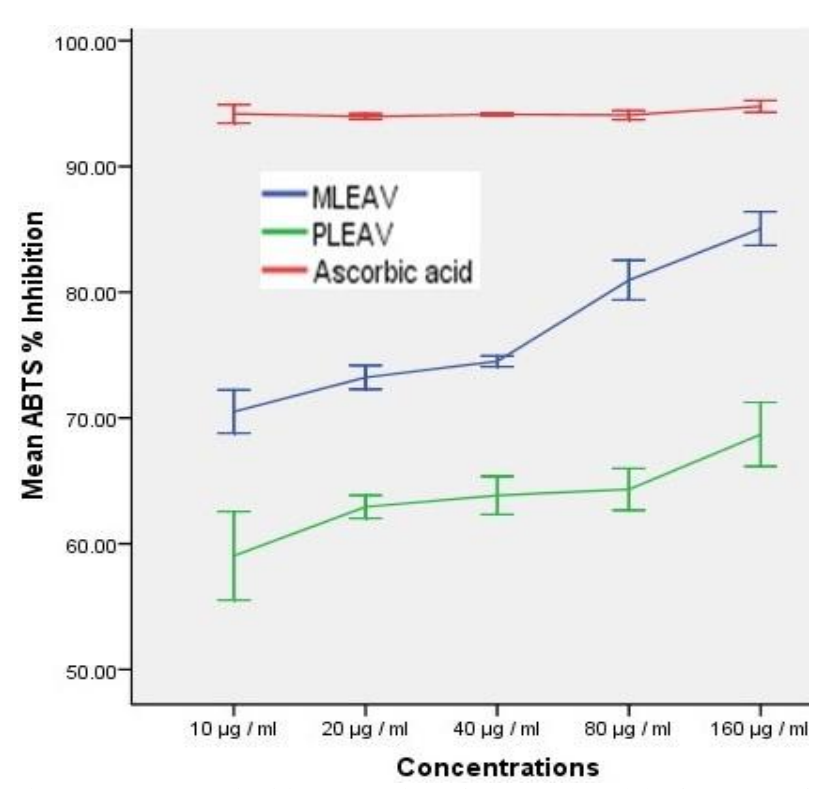

Figure 3 Mean antioxidant capacity of the methanol leaf extract of Asystasia vogeliana (MLEAV) and petroleum ether leaf extract of Asystasia vogeliana (PLEAV) as per $\mathrm{ABTS}^{+}$radical scavenging assay as percentage activity. Results are presented mean \pm SEM $(\mathrm{n}=3)$. MLEAV = Methanol leaf extract of Asystasia vogeliana $;$ PLEAV= Petroleum ether leaf extract of Asystasia vogeliana.

Table 1 Hematological profile of rats pretreated with MLEAV and PLEAV for 5 days against paracetamol toxic dose $2 \mathrm{~g} / \mathrm{kg}$

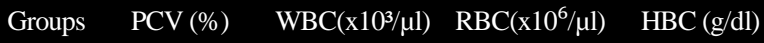

\begin{tabular}{ccccc|}
\hline I & $40.20 \pm 0.49^{\mathrm{b}}$ & $10.88 \pm 0.01^{\mathrm{bc}}$ & $10.54 \pm 0.11^{\mathrm{b}}$ & $11.50 \pm 0.17^{\mathrm{b}}$ \\
\hline II & $39.20 \pm 0.86^{\mathrm{b}}$ & $10.06 \pm 0.03^{\mathrm{cd}}$ & $10.54 \pm 0.04^{\mathrm{b}}$ & $11.94 \pm 0.07^{\mathrm{b}}$ \\
\hline III & $40.20 \pm 0.49^{\mathrm{b}}$ & $10.54 \pm 0.97^{\mathrm{c}}$ & $9.92 \pm 0.17^{\mathrm{a}}$ & $11.12 \pm 0.27^{\mathrm{b}}$ \\
\hline IV & $40.80 \pm 0.37^{\mathrm{b}}$ & $10.68 \pm 0.03^{\mathrm{c}}$ & $10.70 \pm 0.26^{\mathrm{b}}$ & $11.78 \pm 0.11^{\mathrm{b}}$ \\
\hline V & $36.80 \pm 0.86^{\mathrm{a}}$ & $11.52 \pm 0.03^{\mathrm{ab}}$ & $9.65 \pm 0.18^{\mathrm{a}}$ & $10.50 \pm 0.13^{\mathrm{a}}$ \\
\hline
\end{tabular}

Group I received distilled water which served as control; Group II received $200 \mathrm{mg} / \mathrm{kg}$ MLEAV + PCM; Group III received $200 \mathrm{mg} / \mathrm{kg}$ PLEAV + PCM; Group IV received $25 \mathrm{mg} / \mathrm{kg}$ SLM + PCM; Group V received $2000 \mathrm{mg} / \mathrm{kg}$ PCM.DW $=$ Distilled water PCM = Paracetamol SLM = Silymarin; MLEAV = Methanol leaf extract of A. vogeliana PLEAV = Petroleum ether leaf extract of A. vogeliana. Data are expressed in mean \pm SEM $(n=5)$. One-way ANOVA followed by posthoc LSD was adopted. LSD = Mean in the same column with different superscript letter (s) indicates significant difference, $\mathrm{p}<0.05$ comparing all the groups.

respectively. In DPPH radical scavenging assay, ascorbic acid was used as standard. Ascorbic acid showed a significant increase $(P<$ 0.05 ) in DPPH inhibition (> $90 \%$ in all concentrations) when compared with MLEAV ( $\leq 80 \%$ in all concentrations) and PLEAV ( $\leq 65 \%$ in all concentrations). Next to ascorbic acid, MLEAV showed significant $(P<0.05)$ antioxidant activity with increasing concentration $\geq 20 \mu \mathrm{g} / \mathrm{ml}$ as compared to PLEAV.
MLEAV at concentrations $(>20 \mu \mathrm{g} / \mathrm{ml})$ significantly $(P<0.05)$ showed an increasing trend in the ferric reducing power (0.045- 0.06 $\mu \mathrm{MFe}^{2+} / \mathrm{g}$ extract) when compared with gallic acid $\left(<0.035 \mu \mathrm{MFe}^{2+} / \mathrm{g}\right.$ extract) and PLEAV $\left(>0.035 \mu \mathrm{MFe}^{2+} / \mathrm{g}\right.$ extract). At $160 \mu \mathrm{g} / \mathrm{ml}$ concentration, ferric reducing power of MLEAV $\left(>0.06 \mu \mathrm{MFe}^{2+} / \mathrm{g}\right.$ extract) significantly $(P<0.005)$ increased when compared with those of gallic acid and PLEAV $\left(\leq 0.035 \mu \mathrm{MFe}^{2+} / \mathrm{g}\right.$ extract $)$.

Ascorbic acid, MLEAV and PLEAV showed similar increasing trend in antioxidant activity with increase in concentrations. However, ascorbic acid showed significant $(P<0.05)$ increases in $\%$ ABTS $^{+}{ }^{+}$inhibition $(90-\geq 95)$ when compared with MLEAV \% ABTS $^{+}{ }^{+}$inhibition $(70-85)$ and PLEAV \% ABTS $^{++}$inhibition $(60$ $-65)$ in increasing concentrations.

\subsection{Acute toxicity test}

The varying doses of MLEAV used for the acute toxicity test exhibited no adverse clinical effect on the behavioral responses of the experimental rats. No mortality was recorded.

\subsection{Effect of MLEAV and PLEAV on hematology}

The results of the hematological profile of Albino Wistar rats pretreated with MLEAV and PLEAV for 5 days against acetaminophen-induced toxicity are presented in Table 1 . There were no significant changes $(P>0.05)$ in the hematological profile of rats pretreated with MLEAV and PLEAV when compared with control and silymarin groups.

\subsection{Effect of MLEAV and PLEAV on liver and kidney function}

The results of the liver and kidney function parameters of rats pretreated with both MLEAV and PLEAV are presented in Table 2. The extracts and silymarin-pretreated groups significantly $(P<$ $0.05)$ reduced the elevated activities of AST, ALT, ALP, and the level of total bilirubin. There were no significant changes $(P>$ $0.05)$ in the BUN and creatinine levels in group II (4.00 \pm 0.21 ; $2.28 \pm 0.10)$ and III $(4.24 \pm 0.10 ; 2.40 \pm 0.15)$ when compared with Group I ( $4.64 \pm 0.05 ; 2.38 \pm 0.15)$.

\subsection{Effect of MLEAV and PLEAV on in vivo antioxidant profile}

Table 3 presents the results of in vivo antioxidant activities of Albino Wistar rats pretreated with MLEAV and PLEAV for 5 days against paracetamol-induced toxicity. There were no significant differences $(P>0.05)$ in the concentrations of GSH of group pretreated with silymarin $(25 \mathrm{mg} / \mathrm{kg})(13.81 \pm 0.28)$ when compared with groups pretreated MLEAV and PLEAV at 200 $\mathrm{mg} / \mathrm{kg}(15.53 \pm 0.50 ; 14.13 \pm 0.39)$ respectively. Reduced glutathione $(\mathrm{GSH})$ concentration in PCM group $(12.53 \pm 0.32)$ decreased significantly $(P<0.05)$ when compared with those groups pretreated with extracts and silymarin. 
Table 2 Serum liver and Kidney markers of rats pretreated with MLEAV and PLEAV for 5 days against paracetamol toxic dose $2 \mathrm{~g} / \mathrm{kg}$

\begin{tabular}{|c|c|c|c|c|c|c|c|c|}
\hline Groups & AST (IU/L) & ALT (IU/L) & ALP (IU/L) & TBIL (mg/dl) & ALT/ALP & AST/ALT & $\begin{array}{c}\text { Creatinine } \\
(\mathrm{mg} / \mathrm{dl})\end{array}$ & BUN (mg/ml) \\
\hline I & $21.60 \pm 1.47^{\mathrm{a}}$ & $37.00 \pm 3.00^{\mathrm{a}}$ & $45.20 \pm 1.86^{\mathrm{a}}$ & $4.94 \pm 0.24^{\mathrm{d}}$ & 0.82 & 0.58 & $2.38 \pm 0.15^{\mathrm{a}}$ & $4.64 \pm 0.05^{\mathrm{b}}$ \\
\hline II & $22.40 \pm 2.32^{\mathrm{a}}$ & $50.80 \pm 1.36^{\mathrm{b}}$ & $57.40 \pm 2.71^{\mathrm{b}}$ & $3.42 \pm 0.09^{\mathrm{a}}$ & 0.89 & 0.44 & $2.28 \pm 0.10^{\mathrm{a}}$ & $4.00 \pm 0.21^{\mathrm{ab}}$ \\
\hline III & $30.80 \pm 1.02^{\mathrm{b}}$ & $65.80 \pm 1.50^{c}$ & $68.00 \pm 4.82^{\mathrm{c}}$ & $4.08 \pm 0.25^{\mathrm{b}}$ & 0.97 & 0.47 & $2.40 \pm 0.15^{\mathrm{a}}$ & $4.24 \pm 0.10^{\mathrm{b}}$ \\
\hline IV & $17.20 \pm 1.07^{\mathrm{a}}$ & $42.80 \pm 2.08^{\mathrm{a}}$ & $44.00 \pm 1.79^{\mathrm{a}}$ & $3.08 \pm 0.19^{\mathrm{a}}$ & 0.97 & 0.40 & $1.78 \pm 0.10^{\mathrm{c}}$ & $3.72 \pm 0.38^{\mathrm{a}}$ \\
\hline V & $88.40 \pm 1.72^{\mathrm{c}}$ & $110.60 \pm 2.51^{\mathrm{d}}$ & $117.20 \pm 2.82^{\mathrm{d}}$ & $5.84 \pm 0.22^{\mathrm{c}}$ & 0.94 & 0.80 & $3.32 \pm 0.12^{b}$ & $6.02 \pm 0.21^{\mathrm{c}}$ \\
\hline
\end{tabular}

Group I received distilled water; Group II received $200 \mathrm{mg} / \mathrm{kg}$ MLEAV + PCM; Group III received 200 mg/kg PLEAV + PCM; Group IV received 25 mg/kg SLM + PCM; Group V received 2000 mg/kg PCM. DW = Distilled water; PCM = Paracetamol; SLM = Silymarin; MLEAV = Methanol leaf extract of A. vogeliana PLEAV = Petroleum ether leaf extract of A. vogeliana. Data are expressed in mean \pm SEM ( $n=5)$. One-way ANOVA followed by post-hoc LSD was adopted. LSD = Mean in the same column with different superscript letter (s) indicates significant difference, $\mathrm{p}<0.05$ comparing all the groups.

Table 3 In vivo antioxidant profile of rats pretreated with MLEAV and PLEAV for 5 days against paracetamol toxic dose $2 \mathrm{~g} / \mathrm{kg}$

\begin{tabular}{|c|c|c|c|c|}
\hline \multicolumn{2}{|c|}{ Group } & SOD (U/L) & CAT (U/L) & GSH (Mg/ml) \\
\hline I & $1.39 \pm 0.03^{\mathrm{a}}$ & $1.08 \pm 0.20^{\mathrm{b}}$ & $10.49 \pm 0.20^{\mathrm{b}}$ & $47.97 \pm 0.48^{\mathrm{e}}$ \\
\hline II & $1.50 \pm 0.08^{\mathrm{a}}$ & $1.71 \pm 0.11^{\mathrm{a}}$ & $15.53 \pm 0.50^{\mathrm{a}}$ & $80.84 \pm 0.96^{\mathrm{a}}$ \\
\hline III & $1.76 \pm 0.04^{\mathrm{b}}$ & $1.66 \pm 0.10^{\mathrm{a}}$ & $14.13 \pm 0.39^{\mathrm{a}}$ & $83.99 \pm 1.78^{\mathrm{a}}$ \\
\hline IV & $1.82 \pm 0.04^{\mathrm{b}}$ & $1.86 \pm 0.07^{\mathrm{a}}$ & $13.81 \pm 0.28^{\mathrm{a}}$ & $76.03 \pm 2.48^{\mathrm{b}}$ \\
\hline V & $1.43 \pm 0.07^{\mathrm{a}}$ & $0.79 \pm 0.15^{\mathrm{b}}$ & $12.53 \pm 0.32^{\mathrm{c}}$ & $62.93 \pm 0.79^{\mathrm{d}}$ \\
\hline
\end{tabular}

Group I received distilled water which served as control; Group II received $200 \mathrm{mg} / \mathrm{kg}$ MLEAV + PCM; Group III received $200 \mathrm{mg} / \mathrm{kg}$ PLEAV + PCM; Group IV received $25 \mathrm{mg} / \mathrm{kg}$ SLM + PCM; Group V received $2000 \mathrm{mg} / \mathrm{kg}$ PCM. DW = distilled water; PCM = paracetamol; SLM = silymarin; MLEAV = methanol leaf extract of A. vogeliana PLEAV = petroleum ether leaf extract of A. vogeliana. Data are Mean \pm SEM ( $\mathrm{n}=5)$. One-way ANOVA followed by post-hoc LSD was adopted. LSD = Mean in the same column with different superscript letter (s) indicates significant difference, $\mathrm{p}<0.05$ comparing all the groups.

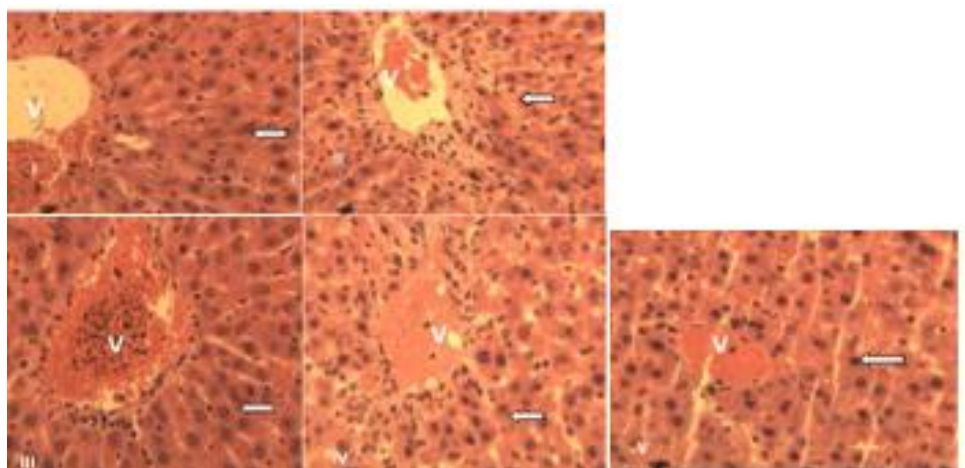

Figure 4 Photomicrograph of sections of the liver from experimental groups. I (CT), II (PCM + MLEAV), III (PCM + PLEAV), IV (PCM + silymarin), V (PCM) rats showing the central vein (V). The hepatocytes (white arrows) were apparently normal in all with no observable histological changes. ( $\mathrm{H}$ and $\mathrm{E} \mathrm{x} 400$ ). MLEAV= Methanol leaf extract of Asystasia vogeliana; $\mathrm{PLEAV}=$ Petroleum leaf extract Asystasia vogeliana $; \mathrm{PCM}=$ Paracetamol $\mathrm{CT}=\mathrm{Control}$.

\subsection{Effect of MLEAV and PLEAV on histopathology of 4 Discussion} paracetamol toxic dose in rats

The histopathological sections of the liver of the experimental groups are presented in Figure 4. The photomicrograph sections of the liver of the experimental groups showed that there were no observable histological changes in the hepatocytes.

DPPH radical can accept an electron as well as hydrogen as its mechanism of stability (Ahmed et al., 2015; Santos-Sánchez et al., 2019). The significant $(P<0.05)$ increase in DPPH free radical scavenging activity of MLEAV ( $\leq 80 \%$ in all concentrations) could indicate the presence of a higher content of protic flavonoids

Journal of Experimental Biology and Agricultural Sciences http://www.jebas.org 
compared with PLEAV ( $\leq 65 \%$ in all concentrations). This supports the conclusion of Prior et al. (2005) that extract with higher polarity has higher free radical scavenging activity. Thus facilitating hydrogen atom transfer (HAT) to occur, this is one of the antioxidant mechanisms of action (Santos-Sánchez et al., 2019; Gulcin, 2020).

MLEAV showed an increasing trend in ferric reducing antioxidant potential with an increase in extract concentration. The tendency of a compound to donate electrons is a vital indicator of its capacity as an antioxidant (Senhaji et al., 2020). Ferric reducing antioxidant potential of MLEAV $\left(>0.06 \mu \mathrm{MFe}^{2+} / \mathrm{g}\right.$ extract) significantly $(\mathrm{P}<$ $0.005)$ increased when compared with those of gallic acid and PLEAV $\left(\leq 0.035 \mu \mathrm{MFe}^{2+} / \mathrm{g}\right.$ extract). This shows that the antioxidant compounds of MLEAV are more electron donors than gallic acid and PLEAV, and thus are likely to minimize the oxidized molecules of lipid perioxidation pathways by playing a role as both primary and secondary antioxidants. Our findings agree with the report of Senhaji et al. (2020) that antioxidants are electron donors and are likely to ameliorate the oxidized molecules of lipid peroxidation pathways by functioning as primary and secondary antioxidants.

In $\mathrm{ABTS}^{+}$assay, MLEAV and PLEAV showed a similar increasing trend in antioxidant activity with an increase in extract concentrations. The significant $(P<0.05)$ increase in antioxidant activity of MLEAV based on decolorization of $\mathrm{ABTS}^{+}$compared with PLEAV in this study reflects the capacity of MLEAV to donate more electrons of hydrogen atoms to inactivate this radical cation in a concentration-dependent manner. This indicates that the free radical scavenging activities of MLEAV may be attributed to its presence of adequate phenolic and flavonoid compounds (Ugwuanyi et al., 2020). Results of the current study are in agreement with the findings reported by Rajurka \& Hande (2010) and Santos-Sánchez et al. (2019) those who reported that phenolic contents strongly correlate with their FRAP and ABTS assays.

The rats tolerated the extract at $5,000 \mathrm{~kg} / \mathrm{mg}$ with no mortality recorded and signs of toxicity. Therefore, the $\mathrm{LD}_{50}$ of MLEAV is beyond $5,000 \mathrm{~kg} / \mathrm{mg}$ (OECD, 2001). The non-significant changes $(P>0.05)$ in the hematological profile could be an indication that the extracts do not have any effect on the hemopoietic system when administered orally at $200 \mathrm{mg} / \mathrm{kg}$ for 5 days. These effects could be attributed to the antioxidant potentials of the extracts as seen in Figures 1, 2, and 3 above.

A significant increase $(P<0.05)$ in the hepatoprotective activity of the MLEAV-treated group, when compared with the PLEAVtreated group, revealed that MLEAV exhibited more phenolic and protic flavonoids contents than PLEAV. These results are supported by the report that the total phenolic contents of MLEAV is significantly $(P=0.000)$ high compared with PLEAV (Ugwuanyi et al., 2020). This is because, phenolics compounds have been associated with antioxidant activity due to their free radical scavenging activities (Rezaie et al., 2015; Santos-Sánchez et al., 2019).

The nonsignificant changes $(\mathrm{P}>0.05)$ in the BUN and creatinine levels in the group II and III compared with group I indicated that both MLEAV and PLEAV protected the kidneys from PCMinduced nephrotoxicity in rats. This effect could be linked with their antioxidant potentials revealed in the in vitro antioxidant activity assays shown in Figures 1, 2, and 3.

The liver injury could be defined as an increase in either ALT activity greater than three times than the upper limit of normal (ULN), ALP activity higher than twice ULN, or total bilirubin level was two times higher than the ULN in relationship with increased ALT or ALP (Mumoli et al., 2006). The ALT activity of rats in group $\mathrm{V}(110.60 \pm 2.51 \mathrm{IU} / \mathrm{L})$ rose more than twice the upper limit of normal (ULN) (5 - 50 IU/L) with attendant increases in total bilirubin, ALP, and ALT. This study showed more than 2 times higher ALT/ALP than the ULN and this thing indicating that there were cholestatic liver damages. These results are in agreement with the findings of Singh et al. (2011) those who suggested that a higher ALT/ALP ratio indicated cholestatic liver damage.

Rats in group V showed a higher AST/ALT ratio (0.80) compared with other groups as shown in Table 2. The higher AST/ALT ratio $(0.80)$ showed in rats of group $\mathrm{V}$ could indicate cholestasis due to extrahepatic obstruction. This supports the findings that AST/ALT ratio $<1.5$ indicates an extrahepatic obstruction of liver damage (Mc Clatchey, 2002; Hall \& Cash, 2012). The reduction in AST/ALT ratio by the extracts and silymarin-pretreated groups was an indication of their antioxidant activities.

The significant decrease $(P<0.05)$ in the concentration of GSH in the PCM group $(12.53 \pm 0.32)$ when compared with pretreated groups of MLEAV (15.53 \pm 0.50$)$, PLEAV (14.13 \pm 0.39$)$, and silymarin $(13.81 \pm 0.28)$ could be attributed to the covalent binding of paracetamol metabolites, N-acetyl-p-benzoquinone imine (NAPQI) to sulfhydryl groups of GSH and various thiol-containing molecules which caused the depletion of GSH. This is because GSH reduction is considered one of the main biochemical markers for paracetamol-induced hepatotoxicity (Akinmoladun et al., 2017). The GPx activity of PCM group (62.93 \pm 0.79$)$ significantly $(P<0.05)$ decreased when compared with pretreated groups silymarin (76.03 \pm 2.48$)$, MLEAV (80.84 \pm 0.96$)$, and PLEAV $(83.99 \pm 1.78)$. The significant $(P<0.05)$ reversal increase in the GPx activity in the sera of rats extracts-pretreated groups indicated their hepatoprotective potentials. This may be one of the key mechanisms mediating the potency for the hepatoprotective activity of the leaf extracts. This agrees with the report that there 
were increases in the activities of antioxidant enzymes such as catalase, glutathione peroxidase, and superoxide dismutase in the administration of the hepatoprotective agent (rosmarinic acid) on the liver (Elufioye \& Habtemariam, 2019). There were no significant differences $(P>0.05)$ in the catalase activity of the pretreated groups with the extracts when compared with the group pretreated with silymarin. The elevation in the enzymatic activities of SOD and CAT indicates that MLEAV and PLEAV improved the enzymatic antioxidant status in rat livers by acting as first-line protection against the damaging effects of superoxide radicals in the liver. This could be because catalase, superoxide dismutase and GPx constitute a "mutually supportive team" of antioxidant defenses and play a vital role in the detoxification of free radicals (Singh et al., 2008; Elufioye \& Habtemariam, 2019).

The histological studies revealed no observable damage of hepatocytes in PCM group; though biochemical analysis showed a high degree of extrahepatic obstruction of liver damage due to cholestasis compared with rats pretreated with MLEAV and PLEAV. The decrease of ALT/ALP, AST/ALT ratios in the serum of rats in groups II and III showed the protective effects of MLEAV and PLEAV against PCM-induced acute hepatotoxicity in rats (Mc Clatchey, 2002; Singh et al., 2011).

\section{Conclusion}

MLEAV elicited more in vitro and in vivo antioxidant activities than PLEAV and said to protect the liver more against paracetamol-induced damage in rats. The strong hepatoprotective effects of MLEAV could be attributed to its antioxidant potentials. Further studies aimed at isolation and characterizations of the active principle (s) of the methanol leaf extract of A. vogeliana are recommended.

\section{Declarations}

\section{Acknowledgement}

The authors are thankful to Prof. A.O. Anaga, the HOD of Veterinary Physiology and Pharmacology for providing the necessary support and facilities for the study.

\section{Authors' contributions}

HE conceived the study, analyzed, interpreted data, and participated in experimental designs. SC and II supervised the work and participated in experimental designs, interpreting of data All the authors have accepted responsibility for the entire content of this submitted manuscript and approved submission.

\section{Conflict of interest statement}

The authors declare that they have no competing interests.

\section{References}

Aebi HE (1983) Catalase. In: Bergmeyer HU (Ed.). Methods of enzymatic analysis. $3^{\text {rd }}$ edition. Deerfield Beach, Florida, Pp.273 286.

Ahmed D, Mehboob K, Saeed R (2015) Comparative analysis of phenolics, flavonoids, antioxidant and antibacterial potential of methanolic, hexanoic and aqueous extracts from Adiantum caudatum leaves. Antioxidants 4: $394-409$.

Akinmoladun AC, Oguntunde KO, Owolabi LO, Ilesanmi OB, Ogundele JO, Olaleye TO, Akindahunsi AA (2017) Reversal of acetaminophen-generated oxidative stress and concomitant hepatotoxicity by a phytopharmaceutical product. Food Science and Human Wellness 6 (1): 20-27.

Ali SA, Al-Amin TH, Mohamed AH and Gameel AA (2009) Hepatoprotective activity of aqueous and methanolic extracts of Capparis decidna stems against carbon tetrachloride induced liver damage in rats. Journal of Pharmacology and Toxicology 4 (4): 167-172.

Ali SA, Sharief NH, Mohamed YS (2019) Hepatoprotective activity of some medicinal plants in Sudan. Evidence-Based Complementary and Alternative Medicine. Volume 2019, Article ID 2196315, 16 pages.

Bancroft JO, Stevens M (2002) Theory and Practice of Histological Techniques. Churchill Livingstone Edinburgh. 16 64.

Benzie IFF, Strain JJ (1999) Ferric reducing / antioxidant power assay: Direct measure of total antioxidant activity of biological fluids and modified version for simultaneous measurement of total antioxidant power and ascorbic acid concentration. Methods in Enzymology 299: 15 - 27.

Biswas K, Kumar A, Babaria B, Prabhu K, Setty R (2010) Hepatoprotective effects of leaves of Peltophorumpterocarpum against paracetamol-induced acute liver damage in rats. Internal Journal of Basic Clinical Pharmacology 1: 10 - 15.

Blass KG, Thiebert RJ, Lam LK (1974) A study of the mechanism of the Jaffe reaction. Journal of Clinical Chemistry and Clinical Biochemistry 12 (7): 336-343.

Bursal E, Gulcin I (2011) Polyphenol contents and in vitro antioxidant activities of lyophilized aqueous extract of Kiwi fruit (Actinidadeliciosa). Food Research International 44: 1482 - 1489.

Coles EH (1968) Veterinary Clinical Pathology. In: Saunders WB. $1^{\text {st }}$ edition. Philadephia and London. $15-17$. 
Ellman GL (1959) Tissue sulfhydryl groups. Archives of Biochemistry and Biophysics 82: 70 - 77.

Elufioye TO, Habtemariam S (2019) Hepatoprotective effects of rosmarinic acid: Insight into its mechanisms of action. Biomedicine \& Pharmacotherapy 112: 108600

Ezzat ZM, Kian A, Bagher MZ, Seyedeh ZM, Omid S (2012) Protective of Fumaria vaillantii extract and monomethyl fumarate on acetaminophen-induced hepatotoxicity in mice. International Journal of Pharmacology 8: 177-184.

Girish C, Koner BC, Jayanthi S, Rao KR, Rajesh B, Pradhan SC (2009) Hepatoprotective activity of six polyherbal formulations in paracetamol induced liver toxicity in mice. Indian Journal of Medical Research 129 (5): 569-578.

Gulcin I (2020) Antioxidants and antioxidant methods: an updated overview. Archive Toxicology 94: 651-715.

Hall P, Cash J (2012) What is the real function of the liver 'function' tests? Ulster Medical Journal 81 (1): 30-36.

Higgins T, Bentler E, Doumars BT (2008) Measurement of hemoglobin in blood. In: Burtis CA, Ashwood ER, Brus DE (Eds.) Tietz Fundamentals of Clinical Chemistry. $6^{\text {th }}$ edition. Saunders, Elsevier, Missouri Pp. 514-515.

Huang D, Ou B, Prior RI (2005) The chemistry behind antioxidant capacity assays. Journal of Agricultural and Food Chemistry 53: $1841-1856$.

Iqbal E, Salim KA, Lim LBL (2015) Phytochemical screening, total phenolics and antioxidant activities of bark and leaf extracts of Goniothalamusveluttinus (Airy shaw) from Brunei Darussalam. Journal of King Saud University Science 27: $224-32$

Liu J, Luo D, Wu Y, Changjun G, Guosheng L, Jinfen C, Wu X, Zhang Q, Cai J and Su Z (2019) The protective effect of Sonnerratia apetala fruit extract on an acetaminophen-induced liver injury in mice. Evidence-Based Complementary and Alternative Medicine e6919834: 12.

Marklund SL (1992) Regulation by cytokines of extracellular superoxide dismutase and other superoxide dismutase isoenzymes in fibroblast. Journal of Biological Chemistry 267: $6696-6701$.

Marnett LJ (2000) Oxyradicals and DNA damage. Carcinogenesis $21: 361-370$.

Mc Clatchey KD (2002) Clinical Laboratory Medicine. $2^{\text {nd }}$ edition. Philadelphia, Lippincott Williams and Wilkins.
Mumolin N, Cei M, Cosimi A (2006) Drug-related hepatotoxicity. New England Journal of Medicine.354: 2191 - 2193.

National Research Council (2010) Guide for the Care and Use of Laboratory Animals. National Academies Press.

OECD (2001) Guideline for testing of Chemicals; Acute oral toxicity-Acute toxic class method. Test Guidelines 423. Organization for Economic Coorporation and Development (OECD), Paris, France.

Okoli F (2015) “'Iba ocha n' anya” translated. Ouigbo 12:28:9

Phaniendra A, Jestadi DB, Periyasamy L (2015) Free radicals: Properties, sources, targets, and their implications in various diseases. Indian Journal of Clinical Biochemistry 30: 11 - 26.

Popoola JO, Adebayo AH, Taiwo OS, Ayepola OO, Okosodo EF (2017) Studies on local knowledge and in vitro cytotoxicity of Moringa oleifera L., Andrographis paniculate N., and Asystasia vogeliana B. extracts. Research Journal of Applied Sciences 12: $180-190$.

Prior RI, Wu X, Schaich K (2005) Standardized methods for the determination of antioxidant capacity and phenolics in foods and dietary supplements. Journal of Agricultural and Food Chemistry 53: $4290-4302$.

Provencher-Bollinger A, Everds NE (2010) Hematology of Laboratory Rodents: Mouse (Mus muscularis) and rats (Rattus norvegicus). In: Weiss DJ, Wadrop KJ (Eds.) Schalm's Veterinary Hematology. $6^{\text {th }}$ edition. Wiley-Blackwell, Ames, IO. P. 852-862.

Rajurka NS, Hande SM (2010) Estimation of phytochemical content and antioxidant activity of some selected traditional Indian medicinal plants. Indian Journal of Pharmaceutical Sciences 73 (2): 146151.

Re R, Pellegrini N, Proteggente A, Pannal A, Yang M, Rice Evans C (1999) Antioxidant activity applying an improved $\mathrm{ABTS}^{+}$radicals cation decolorization assay. Free Radical Biology and Medicine 26:1231-1237.

Rezaie M, Farhoosh R, Iranshahi M, Sharif A, Golmohamadzadeh S (2015) Ultrasonic-assited extraction of antioxidative compounds from Bene (Pistaciaatlantica subsp. mutica) hull using various solvents of different physicochemical properties. Food Chemistry 173: $577-813$.

Rock RC, Walker WG, Hennings CD (1987) Nitrogen metabolites and renal function. ED Tietz NW. In: Fundamental of Clinical Chemistry, $3^{\text {rd }}$ edition. Philadelpia: WB Saunders. Pp. 669-704. 
Rotruck JT, Pope AL, Ganther HE, Hofeman DG, Hockstra WG (1973) Selenium: Biochemical role as component of glutathione peroxidase. Science 4073: 588 - 590 .

Sahreen S, Khan M, Khan R (2010) Evaluation of antioxidant activities of various solvent extracts of Carissa opala fruits. Food Chemistry 122: 1205-1211.

Sahu KG, Khadabadi SS, Bhide T (2009) Evaluation of in vitro antioxidant activity of Amorphophalluscampanulatus (Roxb) Ex Blume Decne. International Journal of Chemical Science 7: 1553 - 1562.

Sahu RK, Kar M, Routrary R (2013) DPPH free radical scavenging activity of some leafy vegetables used by Tribal of Odisha. India Journal of Medicinal plants Studies 1: $21-7$.

Santos-Sánchez FN, Salas-Coronado R, Villanneva-Canongo C, Hernández-Carlos B (2019) Antioxidant compounds and their antioxidant mechanism, antioxidants. Ed Shalaby E. In: Intechopen, DOI: https://doi.org/10.5772/intechopen.85270. Available from: https://www.intechopen.com/books/antioxidantcompounds-andtheir antioxidant-mechanism. Accessed on January, 2020.

Senhaji S, Lamchouri F, Toufik H (2020) Phytochemical content, antibacterial and antioxidant potential of edemic plant Anabasis aretioides Coss \& Moq. (Chenopodiaceae). BioMed Research International, Vol. 2020, Article ID 6152932, 16 pages.

Singh A, Bhat TK, Sharm OP (2011) Clinical Biochemistry of Hepatotoxicity. Journal of Clinical Toxicology S4: ISSN: 2161 0495 - JCT.

Singh N, Kamath V, Narasimhamurthy K, Rajini PS (2008) Protective effects of potato peel extract against carbon tetrachloride-induced liver injury in rats. Journal of Environmental Toxicology and Pharmacology 6: $242-246$.

Stadtman ER, Levine RL (2000) Protein oxidation. Annals of New York Academy of Sciences 899: $191-208$.

Thrall MA, Weiser MG (2002) Hematology. Ed Hendrix CM. In: Laboratory Procedures for Veterinary Technicians. $4^{\text {th }}$ edition. Mosby Inc., Missouri, USA.

Ugwuanyi HE, Aba PE, Udem SC, Madubuinyi II (2020) Acute toxicity and erythrocyte osmotic fragility studies of methanol leaf extract of Asystasia vogeliana in rats. Journal of Applied life Sciences International 23 (2): 18-28.

Yla-Herttuala S (1999) Oxidized LDL and atherogenesis. Annals New York Academy of Sciences 874: 134 - 137.

Journal of Experimental Biology and Agricultural Sciences

http://www.jebas.org 